\title{
From LCT to Power Trio - The Cooperation Between SFL and Sociology
}

\section{Lu Huang, Liping Chen}

School of Foreign Languages and Cultures, Nanjing Normal University, Nanjing, China

\section{Email address:}

huanglu6712482@163.com (Lu Huang),04198@njnu.edu.cn (Liping Chen)

\section{To cite this article:}

Lu Huang, Liping Chen. From LCT to Power Trio - The Cooperation Between SFL and Sociology. International Journal of Education, Culture and Society. Vol. 2, No. 6, 2017, pp. 213-217. doi: 10.11648/j.ijecs.20170206.19

Received: March 21, 2017; Accepted: April 1, 2017; Published: January 10, 2018

\begin{abstract}
Over the past decade, systemic functional linguistics and Legitimation Code Theory (LCT) has been cooperating to offer insight into education, especially knowledge building. In the special issue of Linguistics and Education in 2013, Karl Maton highlights the significance of semantic waves in knowledge building. These semantic waves involve recurrent movements in the semantic gravity and semantic density. Based on this theory, considering the technicality and abstractness of high stake reading and writing expected from students, the functional linguist J. R. Martin put forward the practical concepts of power trio, including power words, power grammar and power composition as tools for teachers to use for purposes of knowledge building from the perspective of lexicon, clause and discourse. In this paper, specific attention is first paid to introduce the development of LCT to power trio. Finally, the paper will move on to raise important issues regarding the problems lies in the theories.
\end{abstract}

Keywords: LCT, Semantic Waves, Power Trio

\section{Introduction}

Everyone in education shares a desire for cumulative knowledge building. It can enable students to build on previous understandings and transfer what they learn into future contexts. Thus, cumulative knowledge building in teaching and learning are at the heart of education. However, research and policy debates are full of concern over segmentalism, which means knowledge is strongly tied to its context that is only meaningful within the context. The two obstacles to enable knowledge building are knowledge blindness and segmental theorizing [1]. Knowledge blindness means knowledge as an object is obscured. This is because the dominant influence by psychology and sociology over recent decades [2]. On the one hand, psychological approaches focus on generic mental process of learning and sideline differences between the forms of knowledge being learnt [1]. Hence, knowledge is reduced to a reflection of mental process. On the other hand, the sociological approaches focus on effects of the power relations of different cultural and social communities on education. Thus, knowledge is reduced to a reflection of social power. Knowledge itself has been backgrounded.

But according to Maton [1], the highlight of knowledge blindness is not to say that there are not any models or theories
Biglan [3], Bloom [4], Schulman [5], and Kolb [6] offered typologies in categorizing knowledge. These models take knowledge as objects. They are the starting point to highlight the knowledge. But they embody a segmental form of theorizing, in ways of expanding or contracting, overlapping or integrating the types of knowledge they delineate [1]. Especially when doing empirical researches, researchers often find difficulties in identifying missing kinds of knowledge. They can't embrace the empirical complexity and variation of all kinds of knowledge. Bernstein's 'discourse' and 'knowledge structure' offers another typological way to categorize knowledge. Bernstein categorize knowledge into horizontal discourse and vertical discourse. Horizontal discourse 'entails a set of strategies which are local, segmentally organized, context specific and dependent, for maximizing encounters with persons and habitats' [7]. Vertical discourse comprises 'specialized symbolic structures of explicit knowledge' [7]. Bernstein's model has inspired a renewed focus in sociology and linguistics on knowledge practices [8] [9] [10]. It brings knowledge-building into the foreground. But he doesn't make it clear what makes horizontal and what makes vertical discourse. And few practices fit into this typological dichotomies, because many combine features of both knowledge structure. 
So to explore how to build cumulative knowledge learning, principally based on the foundational framework of Bernstein's knowledge structure, Maton [1] proposed the notion of LCT. LCT is a practical framework that is being used to explore a host of issues, practices and contexts in education and beyond [11], both on its own and alongside complementary frameworks, especially systemic functional linguistics [12] [13]. There are five dimensions of LCT, namely autonomy, density, specialization, temporality, and semantics, among which, semantics are the most correlated with linguistics, especially SFL.

\section{Semantics: Semantic Waves}

The notions of LCT can be usefully considered from the perspectives of technicality and abstraction in SFL. In the special issue of Linguistics and Education in 2013, Maton first introduces the notions of semantic waves from the dimension of semantics in LCT. As Maton [1] describes, the notion of semantic waves begins from two concepts from LCT: semantic gravity (SG) and semantic density (SD). Semantic

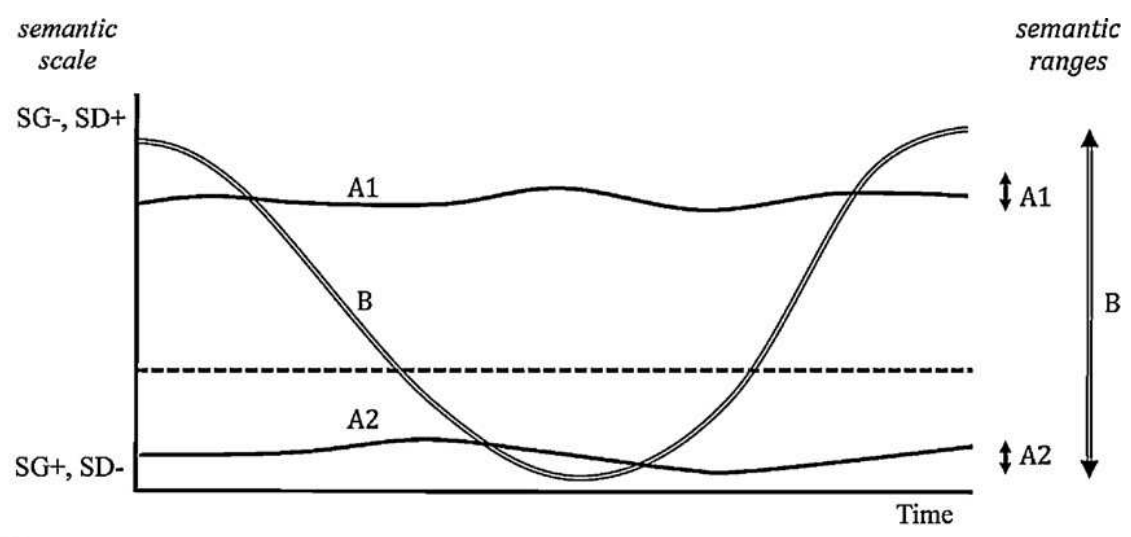

$\underline{\text { Key }}$

$\underline{\mathrm{SG}}=$ semantic gravity; $\mathrm{SD}=$ semantic density; + = stronger; - = weaker

Figure 1. A semantic Wave [1].

Maton [1] emphasizes that a semantic profile characterizing classroom practice in the study involved not only downward semantic shifts but also upward semantic shifts. By using every day language and giving examples or changing the tense, teachers can 'unpack' the semantic file to downward semantic shift. But Maton finds that teachers rarely moving back into the pedagogic discourse which characterized as strong semantic density and weak semantic gravity by using 'repacking' to upward the semantic shift. This phenomenon will cause students stop at the non-technicalized, concretized and often segmented knowledge., thus can't be plugged into re constellation of meanings constituting academic fields. An ideal semantic wave thereby offers the possibility of additionally modelling transitions of knowledge from contextualized and simpler understandings towards more integrated, manifold and deeper meanings. Maton also emphasizes that there is not only one model of semantic wave as shown in figure 1. In the classroom setting, there are various kinds of semantic waves varying in its rage, directions, gravity refers to the degree of context dependence of meaning. Semantic gravity may be relatively stronger $(+)$ or weaker $(-)$ along a continuum of strengths. The stronger the semantic gravity $\left(\mathrm{SG}^{+}\right)$, the more meaning is dependent on its context; the weaker the semantic gravity ( $\left.\mathrm{SG}^{-}\right)$, the less dependent meaning is on its context; Semantic density (SD) refers to the degree of condensation of meaning within socio-cultural practices. Semantic density may be relatively stronger $(+)$ or weaker $(-)$ along a continuum of strengths. The stronger the semantic density $(\mathrm{SD}+)$, the more meanings are condensed within practices; the weaker the semantic density ( $\mathrm{SD}^{-}$), the less meanings are condensed. These concepts can be used in a variety of ways, including to trace changes in knowledge through time as semantic profiles. As Maton [1] explains, for simplicity we here focus on describing semantic profiles using a 'semantic scale' where semantic gravity and semantic density are moving inversely. Figure 1 illustrates a single semantic wave using such a scale. This shows how a semantic wave involves movements between positions higher and lower on the semantic scale, or between weaker and stronger semantic gravity and stronger and weaker semantic density.

$$
\text { semantic }
$$

beginning and ending point.

\section{Power Trio}

From the complementary perspective of SFL, Martin [14] explores the language resources that contribute to creating these semantic waves. Specifically, he introduces the concept of power trio for making more accessible the linguistic features that construe and organize what SFL refers to as 'field'. These comprised highlighting the semantic power of technical terms as 'power words', the knowledge construing power of grammatical metaphor as 'power grammar', and the crafting and organization of whole texts as 'power composition'.

\subsection{Power Words}

Maton's work on 'semantic waves' has rekindled interest in the construal of specialized knowledge in uncommon sense discourse. Maton's notion of condensation of meaning 
naturally invites a response from functional linguists in relation to their work on technicality and the distillation of meaning in academic and professional discourses of various kinds. One important variable in this work was the degree of technicality deployed in a particular field, with technicality explored as a process of distillation - a process whereby meaning is both condensed and reconstituted in lexis construing uncommon sense knowledge of the world [15]. Thus to better understand the semantic waves from the perspective of SFL, Martin [14] introduces the notions of power trio where power words, power grammar and power composition are interacted to constitute specialized discourse in uncommon sense.

From the perspective of LCT, a technical word such as 'ultraviolet' as understood in geography, including its 'value' in the composition (i.e. What are they composed of), classification taxonomies (i.e. what kinds of ultraviolet is), and sequencing (i.e. what processes they participate in) in its semantic net, are assumed to have relatively strong semantic density. There is much more to the meaning of the term than a simple definition affords. Undoubtedly, building up the specialized knowledge of an uncommon sense field involves large numbers of technical terms as well as specialized uncommon sense relations (composition, classification and sequencing) in the discipline. According to Martin [14], specialized knowledge is not in other words a word salad - a collection of unfamiliar words; rather, the relations among the technical terms are critical. Those words with strong semantic density afforded by technical terms and the relations among them are referred as power words [14].

\subsection{Power Grammar}

Martin [14] takes the knowledge construing power of grammatical metaphor as power grammar. Normally, people describe the process in terms of an entity participating in an action in a setting and each entity is realized by a nominal group, and action by a verbal group and the setting by a prepositional phrase. Halliday refers to the matching relation between semantics and grammar as congruent. From the perspective of SFL, grammatical metaphor in general involves a transference of meaning in which lexical item that normally means one thing comes to mean another, quite the same as the concept of 'incongruity' by Halliday. For example:

a Because more people are immigrating to Sydney, properties cost more money. (congruent)

b Due to increased immigration to Sydney, properties cost more money. (incongruent)

c Sydney's immigration growth has led to (caused) increased property costs. (incongruent)

In sentence a, the process is realized by a verbal group 'More people are immigrating to Sydney' while in sentence b $\& \mathrm{c}$, the process is construed by nominal groups 'increased immigration to Sydney and immigration growth'. A process or quality which can be construed as if it was a thing or an entity, it was called experiential metaphor [16]. One major advantage of realizing processes as entities is that activities can be described, classified and qualified. Moreover, recons truing activities and processes as things enable them to become participants and circumstances in other activities. For logical metaphor, till in sentence a, the congruent from is realized by a conjunction 'because' construing the relation (here cause and effect) between one clause and the next, while in sentence $b$ \& c, we use verbal groups 'cause' and prepositional phrases 'due to' to construe the cause and effect relations. One of the reasons that writers use logical metaphors for conjunctions is that they can guide their evaluation of relations between events and arguments. This is a crucial resource for reasoning in fields such as sciences and politics, in which it is important not to overstate cause relations until sufficient evidence has been accumulated. Besides, combining with experiential metaphors, it allows writers to package activity sequences as manageable chunks of information, which is oriented to periodicity, which will be explained in power composition in detail [15]. As just illustrated, grammatical metaphors are important linguistic resource as far as uncommon sense construal of the knowledge are concerned. And it is often regarded as a key linguistic resource for achieving valued academic texts, with researchers identifying its presence in successful language as foundational for constructing text features such as lexical density, cohesion and argument development [17] [18] [19]. In particular, we need to highlight its special role in the definitions which establish power words and in explanations. As far as explanations are concerned, grammatical metaphors play equally critical roles in evaluation, coloring and sequencing. As mentioned above, it is important to mention that grammatical metaphor is also a crucial resource for managing the flow of information in abstract written discourse and for distinguishing the oral and written discourse. Marin [14] emphasizes that it would be impossible to produce scientific knowledge or learn science without being able to use grammatical metaphors.

\subsection{Power Composition}

Power grammar, along with power power words, may also be involved in managing information flow beyond the clause. Power composition is crucial linguistic resource helping students gain control of the organization structure of the relevant genre, phasing power words and power grammar into predictable waves of information flow. Power composition basically means organizing writing as a rhetorical sandwich in which you give readers some idea about what to expect, fulfill these expectations and then review them. It is like 'Introduction- Body-Conclusion' organization recommended for essays [16]. Thus discourse creates expectations by flagging forward and consolidates them by summarizing back. This compositional rhetoric is referred to as periodicity which is used to capture the regularity of information flow in which meanings are packaged to make is easier for us to take them in. It is theorized as waves of information reflecting the development of the discourse, including little waves, bigger waves and tidal waves. In little waves, the peak of prominence at the beginning of the clause is referred to as Theme and the crest at the end of the clause is referred as New. The packaging of discourse as choices of Theme and New in a clause is 
reflected by higher level of phases of discourse in bigger waves. These higher level Themes predict what is going to happen in each phase of the discourse, and higher level News consolidate and distill what has already been developed. In bigger waves, the topic sentence which establishes expectations about how the text will unfold is functioned as hyper Theme and the accumulation of new information which is often distilled in a final sentence is functioned as hyper New. Hyper Theme predicts the pattern of Themes which follow and hyper News consolidated the pattern of News which precede it [16]. Waves of Theme and New extend beyond clauses and paragraphs to much larger phases of discourse in many written discourse. In tidal waves, higher level Themes predicting hyper Themes are reoffered as macro- Themes and higher level News distilling hyper News as macro News. Abstract technical discourse featuring weak semantic gravity and strong semantic density relies heavily on scaffolding of this kind to organize information flow. As Martin emphasized: power composition interacts with power words and power grammar in significant ways. From the perspective of LCT it organizes writing as a series of semantic waves, with semantic density peaking in higher level Macro-Themes and Macro-News; paragraph level Hyper-Themes and Hyper-News scale technicality and abstraction down to a level where it can be specified in lower semantic density discourse (the filling of the rhetorical sandwich). This makes it possible for academic writing to sound both critical and objective, with semantically dense interpretations firmly grounded in evidence [14].

\section{Conclusion}

LCT is being increasingly used alongside concepts from across the framework of SFL. This paper began by introducing the concept of LCT, especially the dimension of semantics, namely semantic waves, realized by semantic density and semantic gravity. Maton's notion of semantic waves invites the interest of SFL as far as technicality and distillation of meaning in academic and professional discourses are concerned. Thus, from the perspective of SFL, Martin put forward the notion of power trio. The technicality, abstractness and the information organization structure of power trio are crucial linguistic recourse to build uncommon sense knowledge in specialized field. Some researches have been taken under the framework of semantic waves and power trio highlight the pedagogical implications. For example, drawing on the complementary theoretical frame works from Legitimation Code Theory and Systemic Functional Linguistics, Macnaught, Maton and Martin [13] explores their implications for teacher training regarding collaborations concerned with classroom interaction and knowledge-building practices. Matriglio, Martin and Maton [20] focuses on classroom pedagogy to illustrate an important strategy for making semantic waves in History teaching, namely temporal shifting and from both linguistic and sociological perspectives, the temporality is demonstrated to show how is it implicated in movements up and down the semantic scale to create semantic waves. $\mathrm{Wu}$ [21] analyzes the features of power trio in science, social and literary English texts in China, aims to find out the pedagogical implications for textbook compilation.

However, there are still some questions left unsolved. As to semantic waves, there aren't any operationalized variables to show which one is $\mathrm{SD}+$ and which one is SD-, which is still too subjective only based on the judgment of the researchers. Still there aren't enough empirical researches to prove the the positive role it plays in cumulative learning and high stake reading. Based on the small sample of copra and classroom observation across only two subjects (biology and history) are not relatively convincible. As far as power trio is concerned. The first problem lies in marking and counting power words when analyzing discourses. Just as the same as the problem in semantic waves, one can't be sure which one can be categorized as a power word and which one can not. It is impossible to evaluate which one is more (less) powerful than the other one. But just as Bernstein says 'a paper is part of a development leading to a new development' [9]. The model made by Maton and Martin will be developed further. Their framework will offer blueprints to keep it rolling.

\section{References}

[1] Maton, K. (2013). Making semantic waves: a key to cumulative knowledge-building. Linguistics and Education, 24 (1), 8-22.

[2] Freebody, P., Maton, K., \& Martin, J. (2008). Talk, text and knowledge in cumulative, integrated learning: A response to 'intellectual challenge'. Australian Journal of Language and Literacy, 31, 188-201.

[3] Biglan, A. (1973a). The characteristics of subject matter in different academic areas. Journal of Applied Psychology, 53 (3), 195-203.

[4] Bloom, B. S. (1976). Human characteristics and school learning. New York: McGraw-Hill.

[5] Shulman, L. S. (1986). Those who understand: Knowledge growth in teaching. Educational Researcher, 15 (2), 4-14.

[6] Kolb, D. A. (1981). Learning styles and disciplinary differences. In Chickering (Ed.), The Modern American College. Jossey-Bass: San Francisco.

[7] Bernstein, B. (2000). Pedagogy, symbolic control and identity: Theory, research, critique. Oxford: Rowman \& Littlefield.

[8] Christie, F., \& Martin, J. R. (Eds.). (2007). Language, knowledge and pedagogy: Functional linguistic and sociological perspectives. London: Continuum.

[9] Christie, F., \& Maton, K. (Eds.). (2011). Disciplinarily: Functional linguistic and sociological perspectives. London: Continuum.

[10] Maton, K., \& Moore, R. (Eds.). (2010). Social realism, knowledge and the sociology of education: Coalitions of the mind. London: Continuum.

[11] Maton, K., Hood, S., \& Shay, S. (Eds.). (2013). Knowledge-building: Educational studies in Legitimation Code Theory. London: Routledge. 
[12] Hood, S. (2010). Appraising research: Evaluation in academic writing. London: Palgrave. Hood, S. (2013). Ethnographies on the move, stories on the rise: An LCT perspective on method in the humanities. In K. Maton, S. Hood, \& S. Shay (Eds.), Knowledge-building: Educational studies in Legitimation Code Theory. London: Routledge.

[13] Macnaught, L., Maton, K., Martin, J. R., \& Matruglio, E. (2013). Jointly constructing semantic waves: Implications for teacher training. Linguistics and Education, 24 (1), 50-63.

[14] Martin, J. R. (2013). Embedded literacy: knowledge as meaning. Linguistics and Education, 24 (1), 23-37.

[15] Martin, J. R. (2014). Revisiting field: "Semantic density" in ancient history \& biology discourse. Paper presented at 41 st International Systemic Functional Congress and Latin-American Systemic Functional Congress, Mendoza, Argentina.

[16] Martin, J. R. \& Rose, D. (2014). Working with Discourse: meaning beyond the clause. Peking: Peking University Press. 188-196.
[17] Byrnes, H. (2012). Conceptualizing FL writing development in collegiate settings: a genre-based systemic functional linguistic approach. In R. M. Manchon (Ed.), L2 writing development: Multiple perspectives (pp. 190e218). Berlin: de Gruyter Mouton.

[18] Schleppegrell, M. J. (2001). Linguistic features of the language of schooling. Linguistics and Education, 12, 43-459.

[19] Schleppegrell, M. J. (2004). Technical writing in a second language: the role of grammatical metaphor. In L. J. Ravelli, \& R. A. Ellis (Eds.), Analysing academic writing: Contextualized frameworks. New York: Continuum.

[20] Matruglio, E., Maton, K. \& Martin, J. R. (2013) Time travel: the role of temporality in enabling semantic wves in secondary school teaching. Linguistics and Education, 21 (1) 38-49.

[21] Wu Geqi \& Zhu Yongsheng. (2016). An analysis of power trio in three different genres in college English text books. Foreign Languages and Their Teaching, 60 (5), 50-58. 